\title{
Rodents as intermediate hosts of Hepatozoon ayorgbor (Apicomplexa: Adeleina: Hepatozoidae) from the African ball python, Python regius?
}

\author{
Michal Sloboda $^{1}$, Martin Kamler $^{1}$, Jana Bulantová $^{2}$, Jan Votýpka $^{2,3}$ and David Modrý ${ }^{1,3}$ \\ ${ }^{1}$ Department of Parasitology, University of Veterinary and Pharmaceutical Sciences Brno, Palackého 1-3, 61242 Brno, Czech \\ Republic; \\ ${ }^{2}$ Department of Parasitology, Faculty of Science, Charles University, Viničná 7, 12844 Prague, Czech Republic; \\ ${ }^{3}$ Institute of Parasitology, Biology Centre, Academy of Sciences of the Czech Republic, Branišovská 31, 37005 České \\ Budějovice, Czech Republic
}

Key words: haemogregarines, Adeleina, Hepatozoon, transmission, ICR mice, life cycle

\begin{abstract}
Two experimental trials were performed to elucidate the role of rodents in the life cycle of Hepatozoon species using snakes as intermediate hosts. In one trial, two ball pythons, Python regius Shaw, 1802 were force fed livers of laboratory mice previously inoculated with sporocysts of Hepatozoon ayorgbor Sloboda, Kamler, Bulantová, Votýpka et Modrý, 2007. Transmission was successful in these experimentally infected snakes as evidenced by the appearance of intraerythrocytic gamonts, which persisted until the end of trial, 12 months after inoculation. Developmental stages of haemogregarines were not observed in histological sections from mice. In another experimental trial, a presence of haemogregarine DNA in mice inoculated with $H$. ayorgbor was demonstrated by PCR in the liver, lungs and spleen.
\end{abstract}

The genus Hepatozoon Miller, 1980 (Adeleina: Hepatozoidae) is comprised of a large assemblage of apicomplexan blood parasites. The life cycle was first elucidated by Miller (1908) in the type species, Hepatozoon muris. In Hepatozoon species parasitizing snakes, initial rounds of merogony occur in the internal organs, with a subsequent appearance of gamonts in the peripheral blood. Mosquitoes are the principal vectors, serving as definitive hosts (e.g. genera Culex, Aedes and Anopheles) (Smith 1996). Infection of the snake host via direct ingestion of the infected mosquito was previously confirmed experimentally by several authors (Ball et al. 1967, 1969, Landau et al. 1972, Bashtar et al. 1984, Nadler and Miller 1984, Lowichik et al. 1993, Telford et al. 2001, 2002, 2004).

Since the ingestion of a mosquito by a snake is unlikely due to its feeding habits, other ways of infection were studied in the past. Various species of hosts, possibly serving as a snake's prey, were found to be susceptible to oral infection with Hepatozoon-infected mosquitoes (Oda et al. 1971, Landau et al. 1972). In these intermediate hosts, dizoic, tetrazoic or hexazoic cysts were localised in liver tissue. Ingestion of such a host resulted in the infection of snakes (Landau et al. 1972). Similarly, tissue cysts were described in the liver of amphibians in experiments with Hepatozoon sipedon naturally infecting the northern water snake, Nerodia sipedon (Smith et al. 1994). The presence of Hepatozoon stages in all three hosts (mosquito-frog-snake) involved in the life cycle was later confirmed by molecular data (Smith et al. 1999). The transmission from snake to snake by congenital infection in ovoviviparous snakes, or by predation in ophidiophagous snake species, was also documented (De Biasi 1971, Telford 1984, Lowichik and Yaeger 1987).

Hepatozoon ayorgbor has been described from the naturally infected ball python, Python regius (Sloboda et al. 2007). In the original descriptive study, the snakes were inoculated by ingestion of infected mosquitoes. In the wild, ball pythons prey exclusively upon rodents and birds (Luiselli and Angelici 1998, Spawls et al. 2004). Considering the assumption that ingestion of mosquitoes by a python is unlikely, the possibility of $H$. ayorgbor transmission through experimentally infected rodents was tested.

\section{MATERIALS AND METHODS}

Origin of the Hepatozoon ayorgbor-positive snake. A ball python naturally infected with $H$. ayorgbor originated from a group of snakes imported by a pet-trader from Ghana in 2005 (Sloboda et al. 2007). Prior to exposure to experimental mosquitoes, a parasitaemia of $1.44 \%$ (percentage of infected erythrocytes) was determined by examination of Giemsa-stained blood smears using an Olympus AX70 microscope (Sloboda et al. 2007). The snake was kept in a glass terrarium $\left(28-30^{\circ} \mathrm{C}\right.$ during the day, $23-26^{\circ} \mathrm{C}$ at night, $12 \mathrm{hr} / 12 \mathrm{hr}$ day/night cycle) and $70 \% \mathrm{RH}$. The snake was fed laboratory mice twice a month. 
Obtaining Hepatozoon ayorgbor oocysts. A colony of $\mathrm{Cu}$ lex quinquefasciatus Say, 1823 reared at the Department of Parasitology, Faculty of Science, Charles University, was used to perform experimental infections. The mosquitoes were maintained in a Plexiglas ${ }^{\mathrm{TM}}$ box (Olejníček 1993). The Hepatozoon ayorgbor-infected Python regius was heated in an incubator $\left(37^{\circ} \mathrm{C}\right)$ for 3 hours and placed overnight to a box with 3-5 day old Culex quinquefasciatus.

Then, engorged females were left in the experimental box and kept at $25^{\circ} \mathrm{C}$ and $70 \%$ humidity in a $12 \mathrm{~h} / 12 \mathrm{~h}$ day/night cycle, with provisions of water and a $10 \%(\mathrm{w} / \mathrm{v})$ sucrose solution. Dissections of mosquitoes were performed 33-35 days post infection (DPI). After being immobilized one minute in a freezer, they were dissected according to the Furman and Catts protocol (1982). Samples of proboscis, salivary gland, gut, fat body and haemocoel were examined using an Olympus AX70 microscope. Oocysts of $H$. ayorgbor were gently removed from the slide with a needle and subsequently mixed with a small amount of basic saline solution $(0.9 \% \mathrm{w} / \mathrm{v}$ Natrii chloridum, Braun).

Experiment No. 1. Three adult female mice $(5 \mathrm{Crl}: \mathrm{CD}$ 1(ICR)BR, AnLab Ltd. Prague, Czech Republic) were used. Two mice (Nos. 1 and 2) were inoculated with an oesophageal tube, each receiving 2 oocysts of $H$. ayorgbor $\left(\sim 10^{2}\right.$ sporocysts). The remaining mouse (No. 3) served as a negative control. The mice were maintained in standard plastic boxes and provided water and dry pellet food ad libitum.

The mice were euthanized by ether overdose at DPI 60 and dissected. Samples of heart, lungs, liver, gut, small and large intestine, spleen, kidney and brain were obtained during necropsy and fixed in $10 \%$ buffered formalin. Histological sections were stained with haematoxylin-eosin.

The remaining liver tissue of two experimentally infected mice (Nos. 1 and 2) was used for experimental inoculations of Python regius ( $P$. regius Nos. 1 and 2). Snakes used in the experiment were imported as juveniles by a private breeder and were approximately three months old on arrival. The absence of haemogregarines was confirmed by weekly examination of blood smears for three months prior to their inoculation. The snakes were kept separately in glass terraria as described previously. Each snake received one gram of liver tissue (snake No. 1 from mouse No. 1 and snake No. 2 from mouse No. 2). The third snake ( $P$. regius No. 3) was kept as negative control and received one gram of liver tissue from the uninfected mouse No. 3.

Examination of the blood smears for haemogregarines was performed weekly during the first three months. Later examinations were performed at longer intervals, until the end of the experiment, 12 months after inoculation.

Experiment No. 2. Based on the results of the first experiment, a second series of experiments was performed in a similar fashion, using four female mice of the same origin. Three mice were inoculated (Nos. 4-6), the remaining one (No. 7) served as negative control. Euthanasia and dissections were performed at 70 DPI. The tissue samples, as described above, were divided; one set was preserved in $10 \%$ formalin and the other was collected in sterile $1.5 \mathrm{ml}$ vials (Eppendorf) and frozen to $-20^{\circ} \mathrm{C}$ for later DNA isolation. To prevent contamination, all dissecting tools were flamed before processing of individual organs. Organs that yielded positive in the PCR assay were processed for histology as described above.

DNA isolation, PCR. The phenol-chloroform method of DNA isolation described by Maslov et al. (1996) was used with slight modifications in all the samples obtained in experiment No. 2. Sediment containing DNA obtained after the procedure was dried and suspended in water, which was subsequently used for PCR diagnosis.

PCR was performed using previously published primers designed by Perkins and Keller (2001); a forward primer specific for haemogregarines HEMO1: 5'TAT TGG TTT TAA GAA CTA ATT TTA TGA TTG-3'; a reverse primer specific to apicomplexan parasites HEMO2: 5'CTT CTC CTT CCT TTA AGT GAT AAG GTT CAC3'. Reactions were performed in a thermocycler (T Personal, Biometra ${ }^{\mathbb{B}}$ ) with the following program: 35 cycles of denaturation at $94^{\circ} \mathrm{C}$ for 1 min, annealing at $54^{\circ} \mathrm{C}$ for $1 \mathrm{~min}$ and extension at $72^{\circ} \mathrm{C}$ for 1 min. The amplified products $(15 \mu \mathrm{l})$, positive control (DNA of $H$. ayorgbor isolated from naturally infected $P$. regius) and a negative control (15 $\mu \mathrm{l}$ of PCR water) were analyzed using electrophoresis on a $1.5 \%$ agarose gel stained with ethidium bromide. The bands were visualised by ultraviolet illumination and documented using Vilber Lourmat photographing equipment.

\section{RESULTS}

\section{Experiment No. 1}

All mice were in a good condition with no behavioural changes. Gross pathological lesions were not observed during the necropsy. Histological examination did not reveal endogenous developmental stages of haemogregarines in any organs of both infected mice.

Intraerythrocytic gamonts of $H$. ayorgbor were detected in both inoculated $P$. regius No. 1 and No. 2, being first observed in the peripheral blood at 67 and 73 DPI respectively. Gamonts persisted in erythrocytes of both snakes until the end of the experiment 12 months post inoculation. The highest level of parasitaemia in both snakes was the same, $0.3 \%$, and the dynamics of infection are shown in Fig. 1. The control snake No. 3 remained negative throughout experiment.

\section{Experiment No. 2}

As with the mice in experiment No. 1, gross changes were not observed upon the dissection. PCR of the tissue samples revealed a positive reaction in two of three experimentally infected mice Nos. 4 and 5. DNA of haemogregarines was detected in the liver and spleen tissue samples in mouse No. 4 (Fig. 2) and in the lungs of mouse No. 5 (Fig. 3). PCR examination of tissues from mouse No. 6 was negative, similarly to mouse No. 7 which served as a negative control. Despite the positive PCR, examination of histological samples of liver and spleen of mouse No. 4 and lungs of mouse No. 5 did not reveal any developmental stages of haemogregarines. 


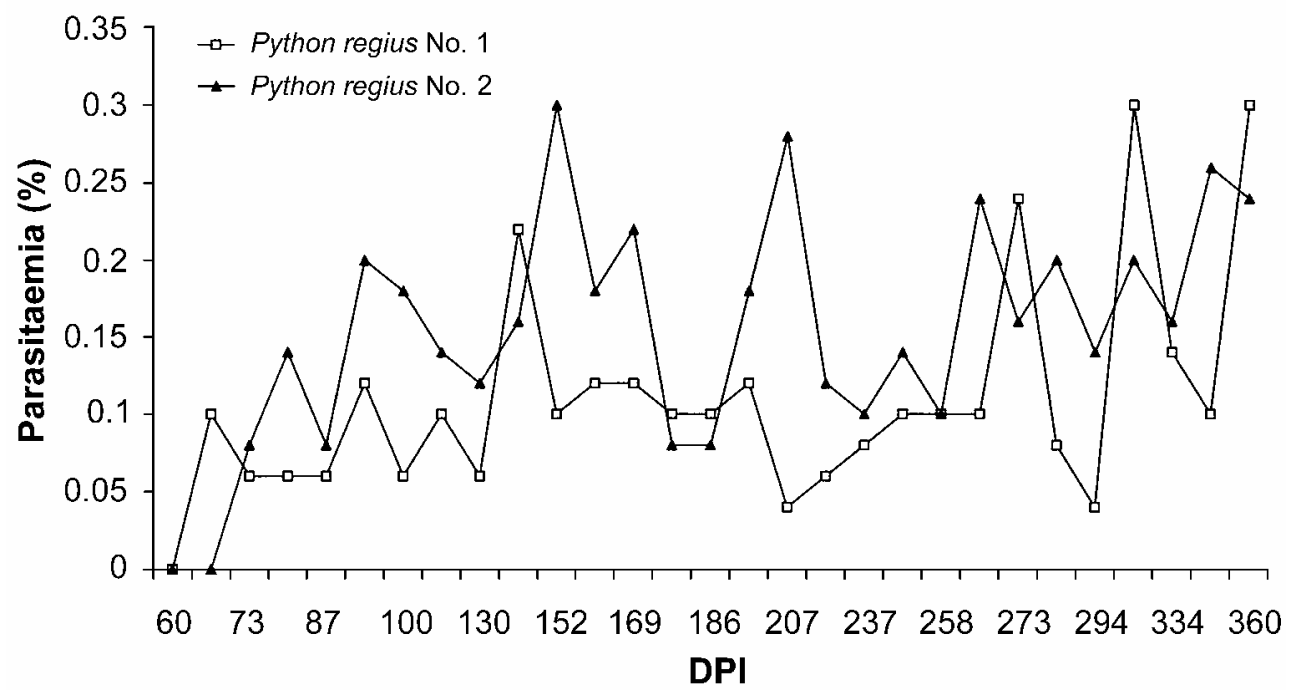

Fig. 1. Parasitaemias in two experimentally infected Python regius. The first intraerythrocytic gamonts of Hepatozoon ayorgbor were observed in snake No. 1 at 67 DPI and in snake No. 2 at 73 DPI. Examination of blood smears was conducted for 12 consecutive months.

\section{2}

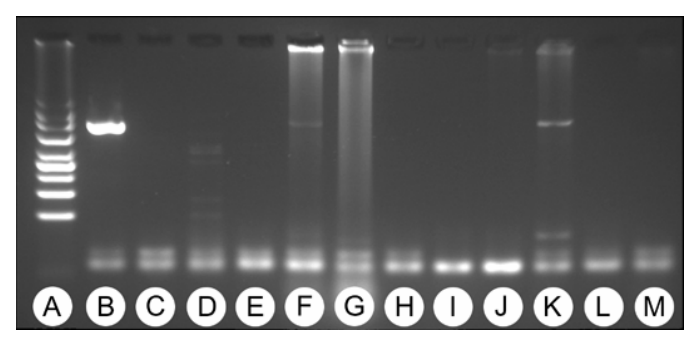

3

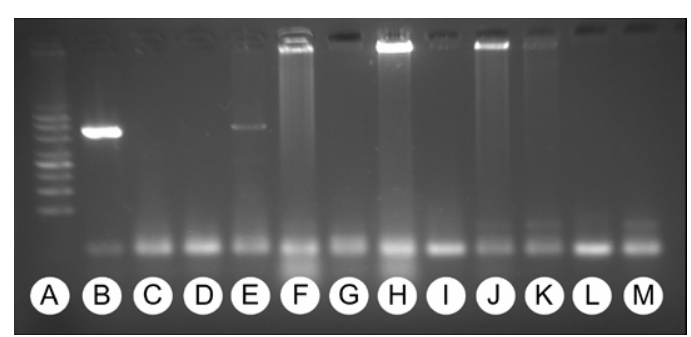

Figs. 2, 3. Results from PCR-based detection of haemogregarine DNA in tissue samples of mice inoculated with sporocysts of Hepatozoon ayorgbor. A - DNA marker, B - positive control, C - negative control, D - heart, E - lungs, F - liver, $\mathrm{G}$ - stomach, $\mathrm{H}$ - small intestine, I - large intestine, $\mathrm{J}$ - kidney, $\mathrm{K}$ - spleen, L - muscle, $\mathrm{M}$ - brain. Fig. 2. Mouse No. 4, positive reaction in liver (F) and spleen (K). Fig. 3. Mouse No. 5 , positive reaction in lungs $(\mathrm{E})$.

\section{DISCUSSION}

Despite the numerous studies on Hepatozoon spp. infecting snakes, the life cycle was elucidated only in a few of them. Direct experimental infection of snakes by feeding them infected mosquitoes was reported in several studies (e.g. Bashtar et al. 1984, Nadler and Miller 1984, Lowichik et al. 1993), and a similar method of experimental transmission was also employed in the original study describing Hepatozoon ayorgbor (Sloboda et al. 2007).

The ingestion of a mosquito by a snake is unlikely; thus, other possible ways of infection were studied. The infection of snakes by ingestion of reptile or amphibian first intermediate hosts has been described (Landau et al. 1972, Lowichik and Yaeger 1987, Smith et al. 1994, Paperna and Lainson 2004). The natural diet of Python regius consists of mammals and birds, primarily of ground-dwelling rodents (Luiselli and Angelici 1998, Spawls et al. 2004). The ingestion of mosquitoes by such intermediate hosts is more likely than the hypothetical direct ingestion by a snake.

In the present study, we clearly demonstrated the transmission of Hepatozoon to a snake host by ingestion of tissues of infected rodents, which suggests the possibility of three-host mosquito-rodent-snake life cycle of $H$. ayorgbor. Despite the fact, that we did not find haemogregarines in the histological sections of infected mice, the PCR assay confirmed the presence of haemogregarine DNA in mice at 70 DPI. Presence of parasite DNA was proven in samples from parenchymatous organs (spleen, liver, lungs), which corresponds to previously published data (Landau et al. 1972). Considering the fact, that mammals are the principal prey for a wide variety of snakes, it is probable that they play a key role in life cycles of several Hepatozoon spp.

Acknowledgements. We wish to thank Petr Fictum for his help with examination of histological samples. This study was supported by grants from the Grant Agency of the Czech Republic (Nos. 524/03/D104 and 524/03/H133) and, in part, also by the Ministry of Education, Youth and Sports of the Czech Republic (MSM0021620828 and LC06009). 


\section{REFERENCES}

BAll G.H., ChaO J., Telford S.R. 1967: The life history of Hepatozoon rarefaciens (Sambon and Seligman, 1907) from Drymarchon corais (Colubridae), and its experimental transfer to Constrictor constrictor (Boidae). J. Parasitol. 53: 897909.

Ball G.H., ChaO J., Telford S.R. 1969: Hepatozoon fusifex sp. n., a hemogregarine from Boa constrictor producing marked morphological changes in infected erythrocytes. J. Parasitol. 55: 800-813.

BASHTAR A.R., ABDEL-GHAFFAR F.A., MEHLHORN H. 1984: Hepatozoon aegypti nov. sp. 3. Electron microscope studies on the gamogony and sporogony inside the vector Culex pipiens molestus. Z. Parasitenkd. 70: 53-65.

DE BIASI P., PESSOA S.B., BELLUOMINI H.E. 1971: Nota sombre a transmissão congenita de hemogregarinas em duas especies de serpentes pe gonhentas viviparas. Atas Soc. Biol. R.J. 15: $27-28$.

FURMAN D.P., CATTS E.P. 1982: Manual of Medical Entomology, 4th ed. Cambridge University Press, New York, $207 \mathrm{pp}$.

LANDAU I., Michel J.C., Chabaud A.G., BRYGOO E.R. 1972: Cycle biologique d'Hepatozoon domerguei; discussion sur les caracteres fondamentaux d'un cycle de coccidie. Z. Parasitenkd. 38: 250-270.

LOWICHIK A., LANERS N.L., LOWRIE R.C., MEINERS N.E. 1993: Gametogenesis and sporogony of Hepatozoon mocassini (Apicomplexa: Adeleina: Hepatozoidae) in an experimental mosquito host. J. Eukaryot. Microbiol. 40: 287-297.

LOWICHIK A., YAEGER R.G. 1987: Ecological aspects of snake hemogregarine infections from two habitats in southeastern Louisiana. J. Parasitol. 73: 1109-1115.

LUISELli L., ANGELICI F.M. 1998: Sexual size dimorphism and natural history traits are correlated with intersexual dietary divergence in royal pythons (Python regius) from the rainforests of southeastern Nigeria. Ital. J. Zool. 65: 183-185.

MASLOV D.A., LUKEŠ J., JIRKU゚ M., SIMPSON L. 1996: Phylogeny of trypanosomes as inferred from the small and large subunit rRNAs: implications for the evolution of parasitism in the trypanosomatid protozoa. Mol. Biochem. Parasitol. 75: 197205.

MiLLER W.W. 1908: Hepatozoon perniciosum n. g., n sp., a haemogregarine pathogenic for white rats; with a brief description of the sexual cycle in the intermediate host, a mite (Laelaps echidninus Berlese). Bull. Hyg. Lab. Wash. 46: 51-123.

NADLER S.A., MiLLER J.H. 1984: A redescription of Hepatozoon mocassini (Laveran, 1902) from Agkistrodon piscivorus leucostoma Troust, 1836. J. Protozool. 31: 321-324.

ODA S.N., CHAO J., BALL G.H. 1971: Additional instances of transfer of reptile hemogregarines to foreign hosts. J. Parasitol. 57: 1377-1378.

Received 3 October 2007
OLEJNÍČEK J. 1993: Plexiglas ${ }^{\mathrm{TM}}$ box system for mosquito rearing. Bull. Soc. Vector Ecol. 18: 38-39.

PAPERNA I., LAINSON R. 2004: Hepatozoon cf. terzii (Sambon \& Selingman, 1907) infection in the snake Boa constrictor constrictor from north Brazil: transmission to the mosquito Culex quinquefasciatus and the lizard Tropidurus torquatus. Parasite 11: 175-181.

PERKINS S.L., KelleR A.K. 2001: Phylogeny of nuclear small subunit rRNA genes of hemogregarines amplified with specific primers. J. Parasitol. 87: 870-876.

SLOBODA M., KAMLER M., BULANTOVÁ J., VOTÝPKA J., MODRÝ D. 2007: A new species of Hepatozoon (Apicomplexa: Adeleorina) from Python regius (Serpentes: Pythonidae) and its experimental transmission by a mosquito vector. J. Parasitol. 93: 1190-1199.

SMITH T.G. 1996: The genus Hepatozoon (Apicomplexa: Adeleina). J. Parasitol. 82: 565-585.

SMith T.G., DESSER S.S., MARTIN D.S. 1994: The development of Hepatozoon sipedon sp. nov. (Apicomplexa: Adeleina: Hepatozoidae) in its natural host, the Northern water snake (Nerodia sipedon sipedon), in the culicine vectors Culex pipiens and $C$. territans, and in an intermediate host, the Northern leopard frog (Rana pipiens). Parasitol. Res. 80: 559568.

SMITH T.G., KIM B., DESSER S.S. 1999: Phylogenetic relationships among Hepatozoon species from snakes, frogs and mosquitoes of Ontario, Canada, determined by ITS-1 nucleotide sequence and life-cycle, morphological and developmental characteristics. Int. J. Parasitol. 29: 293-304.

Spawls S., Howell K., Drewes R., Ashe J. 2004: A Field Guide to the Reptiles of East Africa. A\&C Black Publishers Ltd., London, England, 543 pp.

TELFORD S.R. Jr. 1984: Haemoparasites of reptiles. In: G.L. Hoff, F.L. Frye and E. Jacobson (Eds.), Diseases of Amphibians and Reptiles. Plenum Press, New York, pp. 385-517.

TELFORD S.R. JR., BUTLER J.F., TELFORD R.S. 2002: Hepatozoon species (Apicomplexa: Hepatozoidae) of the corn snake, Elaphe guttata (Serpentes: Colubridae) and the pigmy rattlesnake, Sistrurus miliarius barbouri (Serpentes: Viperidae) in South Florida. J. Parasitol. 88: 778-782.

TELFORD S.R. JR., ERNST J.A., ClARK A.M., BUtLER J.F. 2004: Hepatozoon sauritus: a polytopic hemogregarine of three genera and four species of snakes in North Florida, with specific identity verified from genome analysis. J. Parasitol. 90: 352-358.

TELFORD S.R. JR., WOZNIAK E.J., BUTLER J.F. 2001: Haemogregarine specifity in two communities of Florida snakes, with descriptions of six new species of Hepatozoon (Apicomplexa: Hepatozoidae) and possible species of Haemogregarina (Apicomplexa: Haemogregarinidae). J. Parasitol. 87: 890-905. 